\title{
Intervenção psicológica em terminalidade e morte: relato de experiência ${ }^{1}$
}

\author{
Beatriz Schmidt ${ }^{2}$ \\ Letícia Macedo Gabarra \\ Jadete Rodrigues Gonçalves \\ Universidade Federal de Santa Catarina, Florianópolis-SC, Brasil
}

\begin{abstract}
Resumo: O presente artigo objetivou analisar e refletir sobre a atuação do psicólogo em situações de morte no contexto hospitalar, bem como sobre o processo de terminalidade e despedida para as pessoas enfermas e seus familiares. Utilizou-se relato de experiência profissional através de estudo de caso. Os resultados evidenciaram reconfiguração das relações familiares nos diferentes papéis e funções, na perspectiva de maior autonomia. O ritual de despedida constitui-se em vivência possibilitadora de mudanças e resgates das relações familiares, bem como de elaboração do processo de luto, tanto para o sujeito doente e família quanto para a equipe de saúde.
\end{abstract}

Palavras-chave: morte, aconselhamento psicoterapêutico, psicologia hospitalar, relações familiares.

\section{Psychological intervention in terminality and death: experience report}

\begin{abstract}
This study presents an analysis and reflection upon the practice of psychologists in situations of death in a hospital context, as well as the terminal and farewell process which patients and their family members experience. The experience report of a professional was used through a case study. The results revealed a reconfiguration of family relationships into different roles and functions from the perspective of greater autonomy. The farewell ritual is an experience that enables changes and recovery of family relationships, as well as an opportunity to experience the mourning process, both for patients, their families and health professionals.
\end{abstract}

Keywords: death and dying, psychotherapeutic counseling, hospitals - psychological aspects, family relations.

\section{Intervención psicológica en procesos de duelo y muerte: relato de experiencia}

\begin{abstract}
Resumen: El presente estudio tuvo por objetivo analizar y reflexionar sobre la actuación del psicólogo en situaciones de muerte en el contexto hospitalario, así como sobre el proceso de terminalidad y despedida para las personas enfermas y sus familiares. Se utilizó el relato de experiencia profesional a través de un estudio del caso. Los resultados evidenciaron reconfiguración de las relaciones familiares en los diferentes papeles y funciones en la perspectiva de mayor autonomía. El ritual de despedida se constituye en vivencia posibilitadora de mudanzas y rescate de las relaciones familiares, así como de elaboración del proceso de duelo, tanto para el sujeto enfermo y su familia como para el equipo de salud.
\end{abstract}

Palabras clave: muerte, orientación psicoterapéutica, psicología hospitalaria, relaciones familiares.

A partir da década de 1970, o conceito de saúde começa a ser questionado no que tange à visão dicotômica de saúde e doença, não sendo mais suficiente a antiga concepção de saúde centrada na ausência de enfermidades. Dessa forma, a cura como foco também tende a ser questionada, enfatizando-se a noção de promoção e integralidade da saúde (Buss, 2003; Sebastiani \& Maia, 2005). A aceitação crescente da nova concepção de saúde vem acompanhada do fortalecimento do trabalho em equipe multidisciplinar, à medida que se reconhece a saúde como bem-estar físico, mental e social (Tonneto \& Gomes, 2007).

É nessa conjuntura que se dá a inserção do psicólogo no contexto hospitalar. Segundo Gorayeb (2001), a atuação

${ }^{1}$ Este texto foi revisado seguindo o Acordo Ortográfico da Língua Portuguesa (1990), em vigor a partir de $1^{\circ}$ de janeiro de 2009.

${ }^{2}$ Endereço para correspondência:

Beatriz Schmidt. Rua Sebastião Laurentino da Silva, 126/apto. 718. CEP 88.037-400. Florianópolis-SC, Brasil.E-mail: psi.beatriz@gmail.com desse profissional tem como funções apoiar, esclarecer e informar a pessoa enferma sobre sua doença e prognóstico, bem como favorecer o relacionamento desta com a equipe em todos os âmbitos de suas demandas na instituição hospitalar.

Uma das características do trabalho do psicólogo hospitalar refere-se ao atendimento aos usuários e a seus familiares, especialmente em casos de terminalidade e morte. De acordo com Kübler-Ross (1998), a família da pessoa enferma deve ser levada em consideração, haja vista que o papel dos familiares e suas reações, durante essas situações, influenciam e contribuem sobremaneira nas reações do próprio doente. Além disso, alguns autores apontam que o reconhecimento da unidade família-paciente é imprescindível, levando-se em consideração que, nas situações de terminalidade, costumam aparecer problemas que não foram resolvidos em outros momentos da vida (Borges, Silva, Toniollo, Mazer, \& Santos, 2006; Kübler-Ross, 1998).

Em cursos de graduação na área da saúde, de maneira geral, o cuidado à família dos doentes é pouco abordado 
(Soares, 2007). Contudo, sabe-se que os programas voltados para preparar estudantes a atuar junto a famílias de pessoas em processo de terminalidade apresentam resultados positivos (Fineberg, 2005). Embora o psicólogo, como um profissional de saúde, lide frequentemente com questões relacionadas à morte em seu cotidiano de trabalho, a temática da terminalidade ainda é tratada de maneira incipiente nos cursos de graduação, pós-graduação e extensão, conforme pontuam Junqueira e Kovács (2008).

Nesse sentido, o presente trabalho surge da necessidade de refletir sobre os atendimentos psicológicos realizados em situações de terminalidade e morte no contexto hospitalar, tanto à pessoa doente quanto aos seus familiares; assim como analisar as repercussões da perda para os membros da família. Vale ressaltar que as denominações de "família" foram adotadas compreendendo a pluralidade de composições, que incluem laços consanguíneos ou não, as relações não formalizadas por parentesco e os vínculos entre os membros (Cerveny \& Berthoud, 2009).

Trata-se de um relato de experiência profissional cuja metodologia adotada foi o estudo de caso caracterizado pela apresentação e análise de um ritual de despedida, processo definido, segundo Lisbôa e Crepaldi (2003), como a despedida entre pacientes na iminência da morte e seus familiares. O presente estudo de caso tem como foco o ritual de despedida entre um homem acometido por uma neoplasia, ou seja, por um tumor maligno em estágio avançado, e seus familiares (sua esposa, seus filhos e sua mãe), realizado em uma Unidade de Internação Hospitalar pelo Serviço de Psicologia. Com este estudo pretende-se contribuir para a qualificação do atendimento psicológico prestado ao doente terminal hospitalizado, bem como àqueles que o acompanham.

\section{Morte no ciclo de vida da família}

Diferentes repercussões podem ocorrer por ocasião da perda de um membro no ciclo de vida familiar, o que afeta o risco de disfunção gerado por este evento. A perda do cônjuge em famílias com filhos pequenos é difícil para o parceiro, já que os cuidados com as crianças e as obrigações financeiras permanecem concomitantes à vivência do luto (Walsh \& McGoldrick, 1998). A tristeza do progenitor sobrevivente, aliada à dificuldade de compartilhar esses sentimentos com os filhos, pode gerar distanciamento entre os membros da família e maior impacto na elaboração do luto para a criança (Brown, 2001). Simultaneamente, ocorre o impacto intergeracional nos idosos da família que, em virtude do prolongamento do tempo de vida, acabam enterrando seus filhos adultos e vivenciando, sozinhos, essa perda de difícil elaboração (Kovács, 2008).

A perda do cônjuge, na etapa do ciclo de vida onde a família é composta por filhos ainda crianças ou adolescentes, costuma gerar insegurança na esposa. Por não mais depender do marido, a esposa pode ver-se obrigada a assumir atividades que outrora eram por ele desempenhadas, ajustando-se a exigências novas e sentindo-se solitária por isso (Kübler-Ross, 1998). A morte do progenitor responsável economicamente pela família produz a perda da fonte financeira de sustentação familiar, ocorrendo, consequentemente, desdobramentos adicionais para os membros da família, no sentido de gerar uma nova fonte econômica (Brown, 2001).

Para os filhos pequenos e adolescentes, a perda de um dos pais traz consequências a curto e a longo prazo. Entretanto, a maneira como a criança/adolescente vai lidar com essa perda relaciona-se diretamente com o estado emocional da mãe/pai sobrevivente, com o vínculo que a criança tinha com o progenitor morto e, também, com seu estágio de desenvolvimento cognitivo (Walsh \& McGoldrick, 1998).

As reações apresentadas pelas crianças, quando perdem um dos pais, são bastante diferentes - podem passar do afastamento e isolamento ao pranto convulsivo. Além disso, no período do desenvolvimento em que elas ainda não fazem distinção entre ação e desejo, podem sentir remorso, culpa e responsabilidade na morte de seu progenitor, o que gera temor pela ocorrência de um castigo como revanche (Kübler-Ross, 1998). A morte de um dos pais em famílias com crianças e adolescentes pode suscitar a cristalização das tarefas desenvolvimentais da família, dificultando que os filhos tornem-se independentes, assim como pode transformar um dos filhos em substituto paterno/materno em relação aos irmãos (Brown, 2001).

\section{Intervenção do psicólogo hospitalar em processos de terminalidade e morte}

No ambiente hospitalar, em situações de terminalidade e morte, o processo psicoterápico deve enfatizar a expressão dos sentimentos, a melhora da qualidade de vida e a facilitação da comunicação (Kovács, 1992). Beneficiam-se, dessas intervenções, tanto a pessoa em processo de terminalidade quanto seus familiares, o que diminui a probabilidade de ocorrência de sintomas psicopatológicos futuros, como depressão e ansiedade, decorrentes da perda ou luto não elaborados (Bowlby, 1998; Brown, 2001).

O ritual de despedida entre familiares e pacientes contribui tanto para a prevenção do surgimento desses sintomas psicológicos quanto para a reaproximação da família e para a definição de questões do relacionamento familiar que estejam pendentes (Bowlby, 1998; Imber-Black, 1998; Lisbôa \& Crepaldi, 2003). A partir dele, é possível abrir espaços para o compartilhamento de sentimentos entre os membros da família, incluindo as crianças nesse processo (Bowlby, 1998; Walsh \& McGoldrick, 1998). 
A morte de pessoas gravemente enfermas, no contexto hospitalar, pode ser considerada previsível, de forma que o próprio paciente "prepara-se" psicologicamente para esse evento, assim como seus familiares (Brown, 2001). As doenças progressivas, como o câncer em situação avançada ou não, trazem a expectativa de morte dentro de um período de tempo, permitindo que alguns planejamentos familiares sejam revistos, favorecendo a intervenção psicológica (Parkes, 1998).

As neoplasias indicam um modelo de doença integral, por refletirem a pessoa enferma em suas relações pessoais, sociais e familiares (Moreira \& Mello Filho, 1992). Portanto, nessa perspectiva deve-se pensar na pessoa com câncer como a expressão de um sujeito dentro de um contexto de vida com sua construção histórica e sua rede de relações e significados. O câncer, que corresponde à segunda causa de mortes no Brasil, perdendo apenas para as doenças cardiovasculares é, na verdade, "o nome genérico de um conjunto de mais 200 doenças distintas, com multiplicidade de causas, formas de tratamento, e prognósticos" (Borges e cols., 2006, p. 363). Embora se saiba que as neoplasias são multideterminadas, em alguns grupos sociais há uma associação do câncer como enfermidade punitiva, com conotação moral e religiosa (Aquino \& Zago, 2007). Esse sentimento de culpa parece relacionar-se ao fato de a doença ser percebida como punição em diversas culturas, conforme indicam Sebastiani e Maia (2005).

Como estratégia de enfrentamento da doença, a religião também gera alívio ao sofrimento, oferece o conforto que toma o espaço da fatalidade. Isso se relaciona ao fato de que a explicação oferecida sobre a doença pelos sistemas religiosos se aproxima mais do contexto sociocultural dos pacientes do que aquelas explicações, muitas vezes de uma forma reducionista, oferecidas pela medicina. Em virtude disso, é importante que os profissionais da saúde destacando-se dentre eles os psicólogos - levem em conta a religiosidade do sujeito enfermo ao planejar e executar suas intervenções, contribuindo para a manutenção de uma relação de respeito e confiança com essa clientela (Aquino \& Zago, 2007).

O psicólogo pode estender sua intervenção à equipe profissional da instituição, ao invés de restringi-la apenas ao doente e aos seus familiares. Frequentemente membros da equipe mobilizam-se em situações de terminalidade e morte de pessoas hospitalizadas. Em uma unidade cirúrgica, por exemplo, a equipe de saúde busca salvar vidas de forma heroica, assim, o paciente inoperável e a cirurgia não curativa representam, para eles, um fracasso (Parkes, 1998). A perda do ente querido é dolorosa para quem a experimenta e para quem observa, pelo sentimento de impotência gerado (Bowlby, 1998).

Além disso, o trabalho do psicólogo junto aos outros profissionais deve ocorrer no sentido de uma participação ativa na definição de procedimentos e tratamentos a serem realizados. Para que a prática profissional do psicólogo em ambientes complexos - como é o caso do hospital, onde atuam profissionais de diferentes formações e especialidades - seja bem-sucedida, é imprescindível que o relacionamento entre os membros da equipe seja caracterizado por um diálogo cooperativo e aberto, no qual haja objetividade e clareza na proposição e justificativas de procedimentos técnicos relativos a cada especialidade (Tonetto \& Gomes, 2007). Contudo, parece haver algumas limitações que acarretam lacunas no estabelecimento de relações profissionais com essas características. De acordo com os resultados do trabalho desenvolvido por Gonçalves (2007), embora os profissionais reconheçam a necessidade de atuação de diferentes áreas no trabalho em equipes de saúde, eles demonstram apresentar dificuldades na ação interdisciplinar na prática cotidiana.

\section{Método}

\section{Participantes}

Relata-se o caso de Ivo, 47 anos de idade, casado, pai de dois filhos biológicos e um não biológico, motorista e carregador, com ensino fundamental incompleto. Ivo morava com a esposa Marisa, seus dois filhos mais novos, a nora e o neto. O filho mais velho (do primeiro casamento de Marisa) encontrava-se recluso em um Presídio de Segurança Máxima, condenado judicialmente por tráfico internacional de entorpecentes e aliciamento de menores de idade.

Para melhor elucidar a configuração da estrutura familiar de Ivo no momento do acompanhamento psicológico realizado, optou-se por apresentar, na Figura 1, o genograma familiar, instrumento definido como a representação gráfica que contempla o mapa ou desenho da família com sua estrutura e dinâmica (Böing, Crepaldi, \& Moré, 2008; Wendt \& Crepaldi, 2008). 


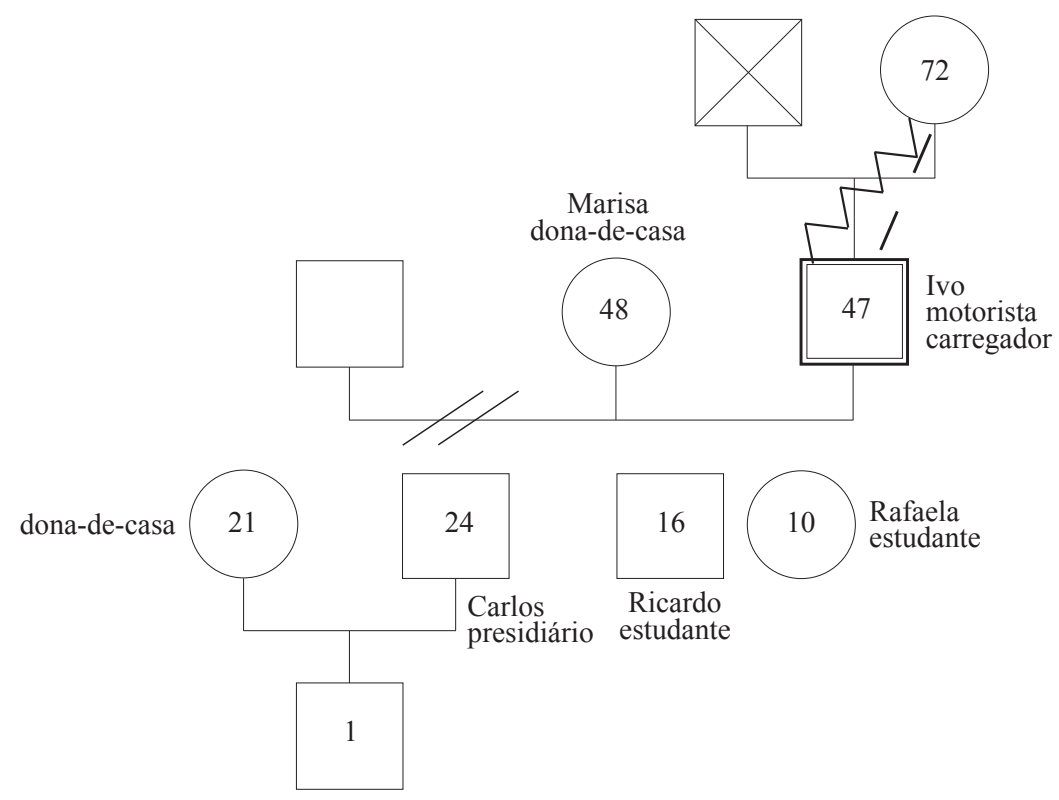

Legenda

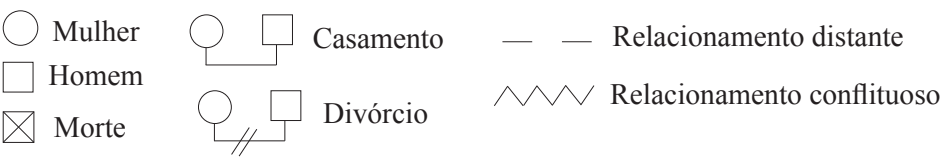

Figura 1. Genograma familiar do caso.

\section{Procedimento}

A internação hospitalar de Ivo ocorreu em um hospital público no Sul do Brasil, em 2008. Ele chegou à instituição para investigação diagnóstica, encaminhado por uma Unidade Básica de Saúde do seu município de origem, relatando declínio acentuado de peso (com perda de aproximadamente 18 quilos durante o período de um ano e seis meses), redução significativa do apetite e intolerância a certos alimentos. O diagnóstico, ao final da investigação, foi de adenocarcinoma gástrico com metástase hepática, ou seja, um câncer localizado, inicialmente, no estômago, mas que já estava presente também no fígado. Para amenizar o desconforto de Ivo e melhorar sua ingesta alimentar, a equipe médica optou por realizar uma gastroenteroanastomose, procedimento que consiste em uma emenda (anastomose) do estômago com o intestino delgado. Serve para desviar os alimentos e as secreções, quando o estômago não é retirado, como foi o caso de Ivo. Toda a família estava ciente do diagnóstico e do prognóstico grave, uma vez que a equipe médica identificou que não havia possibilidade de tratamento curativo, apenas paliativo, visando ao menor desconforto possível ao paciente. Foram 22 dias de hospitalização desde o início da internação até o óbito de Ivo.

O acompanhamento psicológico a Ivo e a seus familiares foi realizado pelo Serviço de Psicologia da Unidade de
Internação do hospital em questão. Os settings de atendimentos foram junto ao leito do paciente, nos corredores da instituição e na Sala do Serviço de Psicologia. As intervenções ocorreram em conjunto com Ivo e sua esposa, bem como com o casal e os dois filhos mais novos e, individualmente (Ivo, sua esposa e a filha). A definição do local e da forma de atendimento (individual ou familiar) ocorreu a partir da demanda apresentada.

Os objetivos dos atendimentos psicológicos foram: esclarecer questões relacionadas à intervenção cirúrgica e às rotinas hospitalares; oferecer suporte emocional ao doente e à sua família em situação de comunicação de prognóstico grave; facilitar e estimular a comunicação entre os familiares e a equipe profissional, utilizando termos e informações francas e factuais; favorecer e autorizar a expressão de sentimentos e a busca de resolução de conflitos ainda pendentes entre os membros da família, possibilitando a comunicação intrafamiliar; reaproximar a família e o doente; reconhecer e encorajar a família a utilizar suas crenças e rituais perante a morte; auxiliar na melhoria da qualidade de vida (conforto na postura física, alimentação possível de satisfazê-lo nessas condições, ambiente acolhedor, disponibilizar recursos que costumava usar em casa para seu bem-estar, mediação com a equipe e família para medicação visando ao alívio dos sintomas) do enfermo na iminência da morte e de sua família, priorizando a minimização do sofrimento e da dor 
sobre a cura da doença; juntamente com a vivência do luto antecipatório, ou seja, aquele que ocorre diante de uma perda iminente, iniciar um processo de reflexão sobre um projeto de vida da esposa e dos filhos, após o óbito; buscar prevenir surgimento de sintomas comprometedores à saúde da nova organização e dinâmica familiar.

\section{Considerações éticas}

Foram tomados todos os cuidados éticos concernentes à proteção dos direitos, bem-estar e dignidade dos participantes. Houve a assinatura do Termo de Consentimento Livre e Esclarecido. Cabe ressaltar que todos os nomes utilizados no presente artigo são fictícios, visando a preservar a identidade do paciente, familiares e membros da equipe.

\section{Resultados e Discussão}

O acompanhamento psicológico começou a ser realizado no segundo dia de hospitalização de Ivo. Ele e sua família já haviam sido comunicados sobre a principal hipótese diagnóstica - adenocarcinoma gástrico com metástase hepática, ou seja, um câncer localizado, inicialmente, no estômago, tendo avançado até o fígado - e o prognóstico grave, caso essa hipótese fosse confirmada. Já no primeiro atendimento, foi possível perceber que o casal apresentava esclarecimento sobre o provável diagnóstico e prognóstico. Ambos usavam a palavra câncer e comunicavam-se abertamente, sem segredos, no que diz respeito à doença.

A gastroenteroanastomose foi realizada no quinto dia de internação, sendo considerada uma cirurgia não curativa, visando a proporcionar apenas condições de alimentação ao doente. No dia seguinte ao procedimento cirúrgico, o médico responsável comunicou ao casal que o câncer apresentava-se em estágio avançado, sendo o tempo de vida de Ivo bastante reduzido. A psicóloga acompanhou a comunicação do diagnóstico, oferecendo suporte emocional a Ivo e sua esposa. Ambos ficaram bastante abalados com as más notícias e, nesse momento, a profissional possibilitou a expressão dos sentimentos de tristeza e medo, "autorizou" o casal a chorar juntos e a compartilhar a dor, ofereceu uma escuta atenta e empática ao sofrimento vivenciado por eles e favoreceu a verbalização dos medos e fantasias.

Nas semanas seguintes, a doença evoluiu, e Ivo teve o seu quadro clínico geral agravado, apresentando intensas dores, náuseas e inapetência. No décimo nono dia de internação, o médico responsável por Ivo solicitou à profissional de psicologia que abordasse, junto à família, a extrema gravidade do caso e a possibilidade de óbito nos dias subsequentes. A partir dos atendimentos realizados até então, a equipe de psicologia entendeu que a família teria condições emocionais de enfrentamento da vivência de despedida, visto que havia aceitado a situação e compreendia a gravidade da doença. Assim, iniciou-se o processo do ritual de despedida entre Ivo e seus familiares, por meio do incentivo à comunicação intrafamiliar, da avaliação de resgates do não dito, do desejo de pedidos de desculpas e agradecimentos entre os membros da família, partindo das necessidades colocadas por eles.

Dessa maneira, nesse mesmo dia foi realizada, pela psicóloga, uma intervenção inicial junto a Marisa e, depois, junto a Ivo, na perspectiva da importância da despedida e de uma maior comunicação entre eles, bem como da expressão dos sentimentos entre os membros da família. Além disso, também foram identificados e discutidos alguns desejos de Ivo expressos a partir do prognóstico. Ivo, católico não praticante desde a adolescência, mencionou que tinha vontade de conversar com o pastor da igreja que sua esposa frequentava. A partir da verbalização de Ivo, Marisa entrou em contato com o pastor que compareceu ao hospital naquela tarde, para rebatizá-lo, atendendo ao seu desejo.

No dia seguinte, a esposa procurou pela psicóloga, informando sobre o "rebatismo" de Ivo e, também, sobre a conversa que o casal havia tido. Ela referiu estar mais tranquila, pois pôde esclarecer com o marido muitas situações conjugais que ainda estavam abertas, relembrar as conquistas e os bons momentos vivenciados pela família e, especialmente, explicitar ao esposo que se sentia culpada por acreditar que sua doença havia se desenvolvido em virtude de toda a tristeza, preocupação e "desgosto" (sic) causado pela prisão de Carlos - filho biológico dela. Marisa relatou que Ivo a tranquilizou quanto a isso, o que diminuiu muito a sensação de culpa que a esposa vinha apresentando, desde a confirmação do diagnóstico de um câncer em estágio avançado.

A psicóloga também evidenciou a importância de membros da família mais próximos afetivamente de Ivo, como os filhos ou outras pessoas que ele quisesse contatar, comparecerem ao hospital para poder se despedir. Como o filho mais velho estava recluso, sem possibilidade de sair da penitenciária, sugeriu-se que a mãe conversasse com ele sobre a situação de Ivo. Ao saber da iminência de morte, Carlos enviou uma carta ao padrasto. A carta foi lida a Ivo pela psicóloga um dia antes da sua morte. Na carta, Carlos informou que havia começado a trabalhar dentro da penitenciária, o que lhe renderia um salário e, também, a diminuição da pena. Assim, ele logo poderia sair para tomar conta da mãe e dos irmãos menores.

Ivo relatou ter ficado mais tranquilo depois de ouvir as palavras escritas por Carlos. Além disso, ele também solicitou à psicóloga que escrevesse um bilhete ao enteado, dizendo que sempre o havia amado, "como se fosse um filho" (sic). Esse bilhete foi entregue a uma sobrinha que o visitava no momento, para ser levado até Carlos.

Os filhos mais novos também puderam ir ao hospital para se despedir do pai. O filho de 16 anos, Ricardo, falou com Ivo rapidamente, e logo quis deixar a Unidade de Internação. A filha permaneceu mais tempo, chorando muito. Marisa solicitou atendimento psicológico individual à Rafaela, que já apresentava dificuldades para dormir e se alimentar.

Nesse atendimento, que ocorreu na sala do Serviço de Psicologia da Unidade, Rafaela referiu que precisava falar 
algumas coisas ao pai, a sós. Mencionou que gostaria de dizer a Ivo que "do céu" ( sic) ele poderia vê-la e teria muito orgulho dela. Disse que queria se desculpar pelos erros e incômodos causados tanto por ela, quanto pelos irmãos. A intervenção da psicóloga foi no sentido de acolhê-la e minimizar a culpa que expressou nessas falas; por outro lado, foi reconhecida sua coragem ao vir se despedir do pai. Identificaram o carinho e o cuidado que Rafaela ofereceu a ele nesse momento, visando a tranquilizá-la sobre sua capacidade amorosa para com os pais e a importância disso na vida deles. A comunicação entre pai e filha foi ressaltada nessa intervenção, permitindo-se a Rafaela sentir e expressar a tristeza pelo adoecimento do pai, bem como poder falar com ele sobre seus sentimentos. Ao sair do quarto, depois dos minutos que esteve a sós com o pai, Rafaela estava mais serena; seu intenso pranto já havia cessado. Pediu para ir embora com a avó materna que a acompanhava.

Em seguida, a psicóloga perguntou a Ivo se havia algo que ele gostaria de solicitar, ou se ainda existiria alguma questão pendente que o afligia. Ivo respondeu que gostaria muito de ver sua mãe, com quem teve uma relação conflituosa e distante desde a adolescência. A esposa já havia entrado em contato com a sogra, residente em uma cidade localizada, aproximadamente, a 400 quilômetros de distância do local de internação de Ivo. Sua mãe chegou ao hospital nesse dia, por volta das 20 horas. Tiveram tempo para conversar e se despedir. Ivo faleceu às 6 horas da manhã seguinte. Ele e seus familiares puderam se despedir, efetivamente. A família enlutada permitiu que Ivo falecesse, bem como o ajudou a realizar as tarefas antes de sua morte (Parkes, 1998).

Mediante o adoecimento e consequente internação hospitalar, importantes mudanças ocorreram na organização familiar, o que levou Marisa e seus filhos a se adaptarem. Marisa passou a assumir atividades que anteriormente eram desempenhadas por Ivo. Em alguns momentos, nas intervenções psicológicas, a esposa demonstrou sentir-se desamparada e sobrecarregada. Orientando-se em Kübler-Ross (1998), entende-se que a perda da segurança e o fato de não mais poder depender do marido contribuíram para que Marisa se sentisse vulnerável frente ao futuro.

A possibilidade de participação e contato com o pai, em seus momentos finais, foi possibilitada aos filhos. Eles puderam estar no hospital e se despedir do pai, cada um a seu modo. Após os minutos em que esteve sozinha com Ivo, Rafaela, ao sair do quarto, demonstrou mais serenidade. Conforme Walsh e McGoldrick (1998), tanto o estágio do desenvolvimento cognitivo quanto a forma como os adultos lidam com a criança no que diz respeito à morte influenciam nas reações que elas apresentam em situações de perda. Caso haja auxílio por parte do genitor sobrevivente, a criança é capaz de entender e participar do luto familiar (Bowlby, 1998; Walsh \& McGoldrick, 1998).

No único atendimento realizado à filha do casal, foi possível perceber que ela estava se sentindo culpada por algo que não soube precisar, talvez por não poder evitar que a morte ocorresse, como se tivesse a capacidade de controlar todos os eventos da vida (Bowlby, 1998). Rafaela referiu que gostaria de falar a sós com o pai para desculpar-se por seus erros. Segundo Kübler-Ross (1998), as reações apresentadas pelas crianças, quando perdem um dos pais, são bastante diferentes e podem passar do afastamento e isolamento ao pranto convulsivo, como o que ocorreu no dia em que Rafaela viu Ivo pela última vez. A autora afirma que, "como as crianças não sabem ainda distinguir entre o desejo e a ação, podem sentir muito remorso e culpa. Podem sentir-se responsáveis por terem matado os pais, daí nascendo o temor de um castigo horrível como represália" (p. 184).

Em diversas culturas o sentimento de culpa relaciona-se ao fato de a doença ser percebida como punição (Sebastiani \& Maia, 2005). Da mesma forma, em determinados grupos sociais há uma associação do câncer como enfermidade punitiva, com conotação moral e religiosa (Aquino \& Zago, 2007). As fantasias quanto à gênese da neoplasia, no caso em questão, ficaram explícitas nos atendimentos realizados à esposa. Marisa referiu, repetidas vezes, acreditar que o câncer do marido havia se desenvolvido pelo desgosto, tristeza e vergonha em virtude da prisão de Carlos, e sentia-se muito culpada por isso. Essa sensação pôde ser amenizada quando, no processo de despedida, a esposa conseguiu explicitar a Ivo o que sentia, sendo por ele acolhida e "liberada" da culpa. A participação intensa da família nos cuidados ao paciente em situações de adoecimento grave atenua a culpa, facilitando o luto após a morte (Kóvacs, 2006).

O adoecimento permite adaptação e transformação gradativas, preparando para a ausência do doente (Brown, 2001; Kübler-Ross, 1998; Parkes, 1998). No caso ora relatado, o processo de adoecimento possibilitou a realização do ritual de despedida com o enfermo ainda em vida. As intervenções psicológicas realizadas visaram a possibilitar aos familiares e a Ivo lidar com a situação vivenciada, conversando sobre questões pendentes, no relacionamento familiar, e estimulando agradecimentos e pedidos de perdão.

O acompanhamento psicológico realizado nesse caso contemplou as características do processo psicoterápico na terminalidade (Junqueira \& Kovács, 2008; Kovács, 1992). Houve uma reaproximação da família, considerada uma das finalidades do ritual de despedida (Imber-Black, 1998; Lisbôa e Crepaldi, 2003). Ivo e Marisa puderam relembrar bons momentos de seu relacionamento e desculpar-se pelos erros cometidos. Os filhos também fizeram o mesmo, inclusive aquele que se encontrava recluso. Além disso, o fato de receber a visita da mãe, com quem teve por longo período de tempo uma relação distante e conturbada, também tranquilizou Ivo que, no último atendimento realizado, afirmou que essa era a única questão ainda pendente em sua vida. $\mathrm{O}$ paciente faleceu logo após conversar com sua genitora. 


\section{Considerações finais}

O processo de despedida com famílias que têm um doente com prognóstico reservado parece beneficiar a todos os envolvidos, isto é, a pessoa enferma, familiares e equipe de saúde. Considerando-se como possível o trabalho de apoio à pessoa enferma no enfrentamento da morte, a redefinição de relações anteriormente comprometidas e o fortalecimento de vínculos mais saudáveis na perspectiva de uma qualidade de vida aos familiares e qualidade de morte ao doente, a equipe de saúde passa a ser protagonista junto a todos os demais atores desse cenário, em busca de recursos saudáveis a esse recorte tão particular da vida das famílias. Assim, o ritual de despedida auxilia as famílias a se tornarem mais próximas, ao mesmo tempo em que se preparam para a separação, como parte integral do processo de vida (Imber-Black, 1998; Lisbôa \& Crepaldi, 2003; Parkes, 1998).

Tal fato aponta para prevenção de sintomas psicológicos futuros naqueles que sofrem a perda, pois além de contribuir para elaboração de possíveis sentimentos de culpa, permite a reelaboração de vivências conflitivas familiares anteriores com ressignificações na dinâmica familiar atual. A possibilidade de realizar um rito de passagem que permita a transição da relação com a pessoa viva para a relação com a pessoa morta é importante na elaboração do luto dos familiares, independente da fase do ciclo de vida em que estejam.

Os resultados observados, com base na intervenção psicológica realizada no período de hospitalização em sua totalidade e, especialmente, no ritual de despedida efetuado nos últimos dias de vida do enfermo, apontaram mudanças qualitativas a partir do trabalho do serviço de psicologia, conforme relatos daqueles envolvidos no processo. No entanto, apesar dos resultados positivos observados no trabalho desenvolvido, novas pesquisas precisam ser realizadas, a fim de que se investigue mais profundamente o impacto da realização do ritual de despedida no enfrentamento e na aceitação da morte, bem como na elaboração do luto após a perda do familiar.

Além disso, pontua-se também a necessidade de abrir mais espaços para a abordagem do tema da morte nos currículos dos cursos de graduação, pós-graduação e extensão em Psicologia, considerando que se refere a um processo natural do desenvolvimento humano e que faz parte do cotidiano de trabalho do psicólogo. De igual importância é a qualificação das demais áreas da saúde, bem como a preparação desses profissionais para atuarem de forma integrada, interdisciplinarmente, como desafio fundamental para uma concepção de saúde na qual trabalhar o processo de morte signifique a vida.

\section{Referências}

Aquino, V. V., \& Zago, M. M. F. (2007). O significado das crenças religiosas para um grupo de pacientes oncológicos em reabilitação. Revista Latino-Americana de Enfermagem, 15(1), 1-6.
Böing, E., Crepaldi, M. A., \& Moré, C. L. O. O. (2008). Pesquisa com famílias: Aspectos teórico-metodológicos. Paidéia (Ribeirão Preto), 18(40), 251-266.

Borges, A. D. V. S., Silva, E. F., Toniollo, P. B., Mazer, S. M., Valle, E. R. M., \& Santos, M.A. (2006). Percepção da morte pelo paciente oncológico ao longo do desenvolvimento. Psicologia em Estudo, 11(2), 361-369.

Bowlby, J. (1998). Perda: Tristeza e depressão (V. Dutra, Trad.). São Paulo: Martins Fontes.

Brown, F. H. (2001). O impacto da morte e da doença grave sobre o ciclo de vida familiar. In B. Carter \& M. McGoldrick (Orgs.), As mudanças no ciclo de vida familiar: Uma estrutura para terapia familiar (pp. 393414). Porto Alegre: Artmed.

Buss, P. M. (2003). Uma introdução ao conceito de promoção da saúde. In D. Czeresnia \& C. M. Freitas (Orgs.), Promoção da saúde: Conceitos, reflexões, tendências (pp. 15-38). Rio de Janeiro: Ed. Fiocruz.

Cerveny, C. M. O., \& Berthoud, C. M. E. (2009). Ciclo vital da família brasileira. In L. C. Osório \& M. E. P. Valle (Orgs.), Manual de terapia familiar (pp. 25-37). Porto Alegre: Artmed.

Fineberg, I. C. (2005). Preparing professionals for family conferences in palliative care: Evaluation results of an interdisciplinary approach. Journal of Palliative Medicine, 8(4), 857-866.

Gonçalves, J. R. (2007). O profissional de saúde em enfermaria de crianças gravemente enfermas $e$ as implicações do cotidiano do trabalho na sua saúde. Tese de doutorado não publicada, Universidade Federal de Santa Catarina, Florianópolis.

Gorayeb, R. (2001). A prática da psicologia hospitalar. In M. L. Marinho \& V. E. Caballo (Orgs.), Psicologia clínica e da saúde (pp. 263-278). Londrina: Ed. UEL-APICSA.

Imber-Black, E. (1998). Os rituais e o processo de elaboração. In F. Walsh \& M. McGoldrick (Orgs.), Morte na família: Sobrevivendo às perdas (pp. 229-245). Porto Alegre: Artmed.

Junqueira, M. H. R., \& Kovács, M. J. (2008). Alunos de psicologia e a educação para a morte. Psicologia: Ciência e Profissão, 28(3), 506-519.

Kovács, M. J. (1992). Morte e desenvolvimento humano. São Paulo: Casa do Psicólogo.

Kovács, M. J. (2006). Comunicação em cuidados paliativos. In C. A. M. Pimenta, D. D. C. F. Mota, \& D. A. L. M. Cruz (Orgs.), Dor e cuidados paliativos: Enfermagem, medicina e psicologia (pp. 86-102). Barueri, SP: Manole.

Kovács, M. J. (2008). Desenvolvimento da tanatologia: Estudos sobre a morte e o morrer. Paidéia (Ribeirão Preto), 18(41), 457-468.

Kübler-Ross, E. (1998). Sobre a morte e o morrer (P. Menezes, Trad.). São Paulo: Martins Fontes.

Lisbôa, M. L., \& Crepaldi, M. A. (2003). Ritual de despedida em familiares de pacientes com prognóstico reservado. Paidéia (Ribeirão Preto), 13(25), 97-109. 
Moreira, M. D., \& Mello Filho, J. (1992). Psicoimunologia hoje. In J. Mello Filho (Org.), Psicossomática hoje (pp. 119-151). Porto Alegre: Artes Médicas.

Parkes, C. M. (1998). Luto: Estudos sobre a perda na vida adulta (M. H. P. Franco, Trad.). São Paulo: Summus.

Sebastiani, R.W, \& Maia, E. M. C. (2005). Contribuições da psicologia da saúde-hospitalar ao paciente cirúrgico. Acta Cirúrgica Brasileira, 20(1), 50-55.

Soares, M. (2007). Cuidando da família de pacientes em situação de terminalidade internados na unidade de terapia intensiva. Revista Brasileira de Terapia Intensiva, 19(4), 481-484.

Tonetto, A. M., \& Gomes, W. B. (2007). A prática do psicólogo hospitalar em equipe multidisciplinar. Estudos de Psicologia, 24(1), 89-98.

Walsh, F., \& McGoldrick, M. (1998). A perda e a família: Uma perspectiva sistêmica. In F. Walsh \& M. McGoldrick (Orgs.), Morte na família: Sobrevivendo às perdas (pp. 27-55). Porto Alegre: Artes Médicas.

Wendt, N. C., \& Crepaldi, M. A. (2008). A utilização do genograma como instrumento de coleta de dados em pesquisa qualitativa. Psicologia: Reflexão e Crítica, 21(2), 302-310.

Beatriz Schmidt é mestranda do Programa de Pós-graduação em Psicologia da Universidade Federal de Santa Catarina.

Letícia Macedo Gabarra é Doutora pelo Programa de Pósgraduação em Psicologia da Universidade Federal de Santa Catarina.

Jadete Rodrigues Gonçalves é Professora Doutora do Departamento de Psicologia da Universidade Federal de Santa Catarina.

Recebido: 27/01/2010

$1^{a}$ revisão: 06/04/2010

$2^{a}$ revisão: 03/09/2010

Aceite final: 21/10/2010 